\title{
ARTROPLASTIA INTERPOSICIONAL PARA TRATAMENTO DE ANQUILOSE DA ARTICULAÇÃO TEMPOROMANDIBULAR
}

\author{
Leonardo Morais Godoy Figueiredo
}

Cirurgião-Dentista,Residente de Cirurgia

Bucomaxilofacial, Departamento de Cirurgia

Bucomaxilofacial da Universidade Federal da

Bahia.

\section{Rômulo Oliveira de Hollanda Valente}

Cirurgião-Dentista, mestre em Cirurgia

Bucomaxilofacial pela Pontifícia Universidade

Católica do Rio Grande do Sul. Doutorado em

Estomatologia pela da Universidade Federal da

Bahia/Universidade Federal da Paraíba. Cirurgião

Bucomaxilofacial do Hospital Getúlio Vargas e do

Instituto de Medicina Integral Prof. Fernando

Figueira, Recife-Pe.

\author{
Thaís Feitosa Leitão de Oliveira \\ Cirurgiã-Dentista, Doutoranda em Estomatologia \\ pela Universidade de São Pauo, Bauru.
Viviane Almeida Sarmento Doutorado em Estomatologia Clínica pela
Pontifícia Universidade Católica do Rio Grande do
Sul. Professora associada da Faculdade de
Odontologia da Universidade Federal da Bahia.

Endereço para correspondência: leo_m_godoy@hotmail.com

\begin{abstract}
Resumo
Introdução: A anquilose da articulação temporomandibular (ATM), é uma patologia limitante causando distúrbios na mastigação, digestão, fonação, aparência e higiene. Objetivo: Relatar um caso clínico de anquilose da ATM diagnosticado em fase adulta e discutir os aspectos envolvidos no seu tratamento, assim como a utilização do retalho de músculo temporal na cirurgia reconstrutiva da ATM. Descrição do Caso: Paciente com 39 anos de idade, do gênero feminino, com abertura bucal de 4 milimetros, foi diagnosticada com anquilose da ATM esquerda, tratada cirurgicamente por meio de artroplastia interposicional com retalho do músculo temporal, evoluindo com abertura bucal de 20 milímetros após 2 meses de cirurgia. Conclusão: A artroplastia interposicional com retalho do músculo temporal representa uma excelente alternativa para o tratamento de paciente com anquilose da ATM em fase adulta, por se tratar de um material de interposição autógeno. O resultado satisfatório do tratamento deve ser atribuído à correta escolha da técnica cirúrgica e ao acompanhamento fisioterápico e fonoaudiológico rigoroso.
\end{abstract}

Palavras-chave: Anquilose; Articulação Temporomandibular; Infecção; Artroplastia.

\section{INTERPOSITIONAL ARTHROPLASTY FOR TREATMENT TEMPOROMANDIBULAR JOINT ANKYLOSIS}

\begin{abstract}
Introduction: Temporomandibular joint (TMJ) ankylosis is an extremely disabling affliction that causes problems in mastication, digestion, speech, appearance, and hygiene. Objective: Report a case of TMJ ankylosis diagnosed in adulthood and discusses the aspects involved in their treatment, and the use of temporal muscle flap in reconstructive surgery of the TMJ. Cases description: 39 year-old female with mouth opening of $4 \mathrm{~mm}$, was diagnosed with left TMJ ankylosis and treated by arthroplasty with interpositional temporalis muscle flap, progressing with mouth opening of $20 \mathrm{~mm}$ after two months out surgery. Conclusion: Despite the numerous surgical techniques for the treatment of TMJ ankylosis, it is still a great challenge, because of high rates of recurrence, which is associated with several factors including age, time of onset, surgical technique, and postoperative care performed. Therefore, it is necessary not only an interdisciplinary team to establish a
\end{abstract}

Revista Bahiana de Odontologia. 2013 out;4(2):129-137

http://www.bahiana.edu.br/revistas 
complete and adequate treatment, but also to carry out a correct and early diagnosis in order to establish a treatment the prognosis is favorable to the patient.

Keywords: Ankylosis; Temporomandibular joint; Infection; Arthroplasty.

\section{INTRODUÇÃO}

A anquilose da articulação temporomandibular (ATM), refere-se à união intra-capsular do complexo disco-côndilo à superfície articular do osso temporal, restringindo dessa forma os movimentos mandibulares. ${ }^{(1,2,3)}$ A etiologia pode ser associada a diversos fatores, como: trauma, radioterapia, cirurgias para excisão de tumores da ATM, artrite reumatóide e infecção. ${ }^{(3)}$ A anquilose da ATM pode prejudicar o crescimento mandibular em indivíduos em fase de crescimento, causando posteriormente uma assimetria facial e micrognatia mandibular. A assimetria mandibular é caracterizada por um desvio da região mentual para o lado afetado, observando-se uma retrognatia acentuada. A anquilose da ATM pode comprometer as funções do sistema estomatognático como diminuição da capacidade mastigatória, dificuldade de fonação, limitação da higiene bucal, problemas respiratórios, erupção anormal dos molares inferiores em pacientes pediátricos. ${ }^{(4,5)}$ As anquiloses podem ser classificadas de acordo com a localização (intra-articular ou extra-articular), tipo de tecido envolvido (ósseo, fibroso ou misto) e na extensão da fusão (completa e incompleta). ${ }^{(5)}$

Três técnicas básicas foram desenvolvidas para o tratamento cirúrgico da anquilose da ATM:

a) Artroplastia em "GAP" ou lacuna - Ressecção da massa óssea entre a cavidade articular e o ramo da mandíbula sem material interposicional. ${ }^{(6)}$

b) Artroplastia interposicional - criação de uma lacuna através da ressecção da massa óssea seguido pela interposição de um material biológico ou material não biológico. A interposição de material no espaço criado após a ressecção da massa anquilótica impede a recidiva da anquilose na ATM após a artroplastia, uma variedade de materiais tem sido utilizada, incluindo materiais biológicos como: fáscia do músculo temporal, derme, cartilagem auricular e materiais não biológicos como: silicone e acrílico. $^{(6,7)}$

c) Reconstrução conjunta da ATM- Ressecção da massa óssea e reconstrução com enxerto de osso autógeno ou prótese articular total. ${ }^{(6)}$ 
O presente artigo tem por objetivo relatar um caso de anquilose da ATM, tratada por artroplastia interposicional com retalho do músculo temporal.

\section{RELATO DE CASO}

Paciente com 39 anos, gênero feminino foi encaminhada pela clínica de Otorrinolaringologia do Hospital de Clínicas da UFPE (HC/UFPE) à clínica de cirurgia Bucomaxilofacial do referido hospital, relatando hipomobilidade mandibular. $\mathrm{Na}$ sua história médica pregressa foram relatados episódios recorrentes de otite média. Ao exame físico extrabucal notou-se dificuldade de abertura bucal, a paciente não excedia $5 \mathrm{~mm}$ de abertura bucal (Figura 1). A radiografia panorâmica dos maxilares e a tomografia computadorizada demonstraram a presença da massa de densidade óssea unindo o côndilo mandibular esquerdo à cavidade articular do osso temporal ipsilateral (Figuras 2 a e b). Diante do quadro apresentado pela paciente o diagnóstico foi de anquilose da ATM e foi proposta uma artroplastia interposicional com remodelação do côndilo. O tratamento cirúrgico foi realizado sob anestesia geral e acesso pré-auricular modificado por Al-Kayat e Bramley ${ }^{(8)}$ (Figura 3 ). Após o acesso realizou-se a osteotomia da parte lateral do bloco ósseo com um motor cirúrgico e uma broca $\mathrm{n}^{\mathrm{o}} 702$ e complementou-se a osteotomia da parte medial da massa com auxilio de um cinzel e martelo, tomando-se cuidado com a parte medial que se encontrava em íntima relação com a artéria maxilar. Após liberação da massa óssea remodelou-se a cavidade articular e o côndilo. Realizou-se a rotação do retalho do músculo temporal sobre o arco zigomático, (Figura 4) e em seguida foram feitos movimentos de abertura e fechamento para confirmar a liberação das interferências causadas pela anquilose. Finalizando o procedimento, foi realizada a sutura por planos e a instalação de um dreno para prevenir infecções e edema. Após 60 dias de cirurgia, a paciente retornou ao serviço para avaliação, quando foi verificada uma abertura bucal de 20 milímetros, e ausência de comprometimento das funções do nervo facial (Figura 5). A paciente foi encaminhada para realização de sessões de fisioterapia ainda no leito hospitalar, com sessões semanais por seis meses com acompanhamento de fonoaudiólogos e fisioterapeutas. Após o primeiro ano de acompanhamento a paciente permanecia com abertura bucal de 20 milimetros. A paciente encontra-se em proservação há 8 anos sem sinal de recidiva.

Revista Bahiana de Odontologia. 2013 out;4(2):129-137 


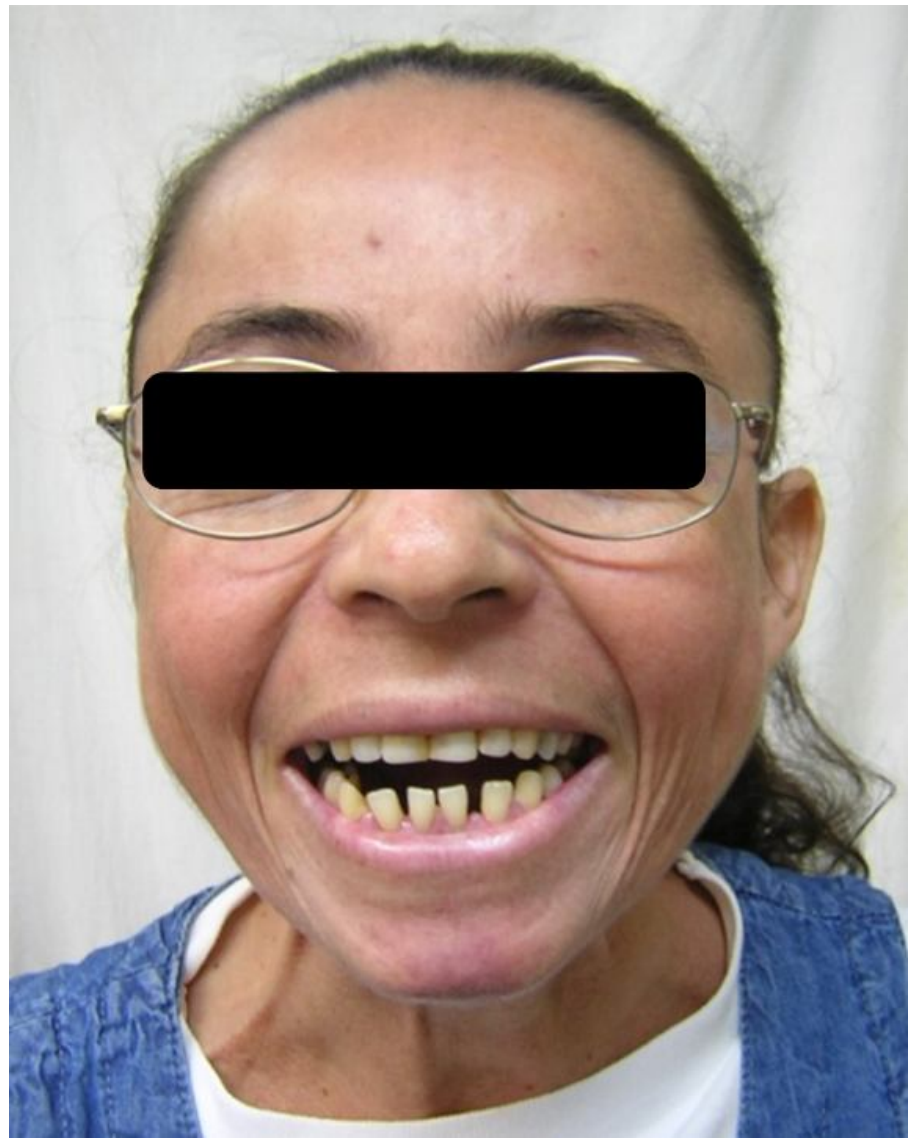

Figura 1 - Paciente em vista frontal observa-se limitação de abertura bucal (4mm), durante o exame clínico inicial
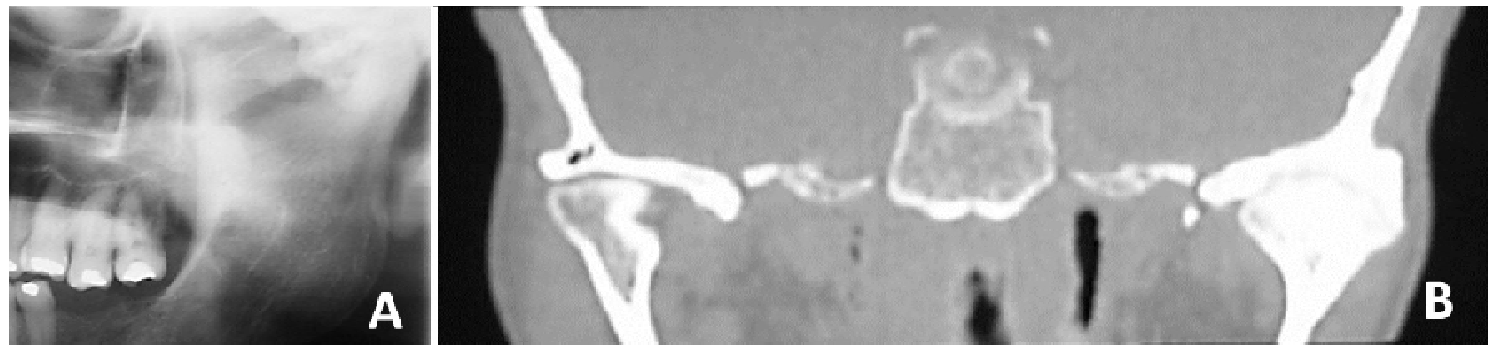

Figura 2 - a) Radiografia panorâmica observa-se imagem sugestiva de anquilose em ATM esquerda b) Tomografia computadorizada em corte coronal observa-se imagem hiperdensa sugestiva de anquilose em ATM esquerda

Revista Bahiana de Odontologia. 2013 out;4(2):129-137

http://www.bahiana.edu.br/revistas 


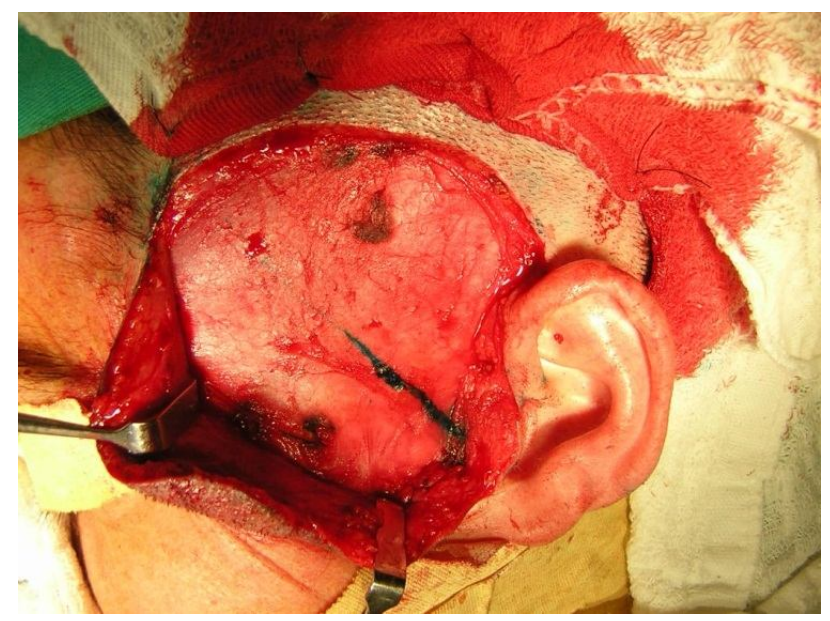

Figura 3 - Acesso para ATM descrito por Al-Kayat e Bramley ${ }^{(8)}$

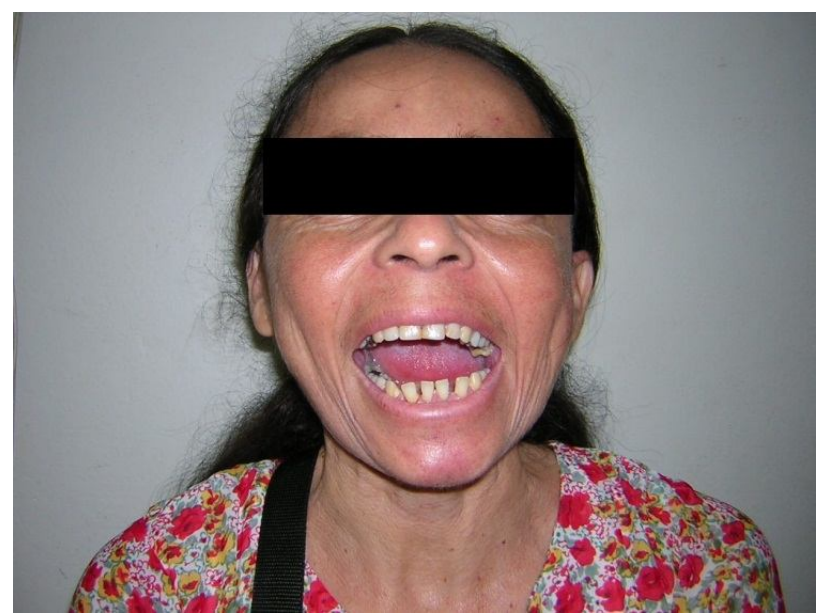

Figura 4 - Paciente em vista frontal, observa-se abertura bucal de $20 \mathrm{~mm}$ após um ano de acompanhamento

\section{DISCUSSÃO}

A anquilose da ATM pode ser classificada em anquilose verdadeira (intracapsular) e pseudoanquilose (extracapsular). A anquilose verdadeira da ATM pode ser definida como uma condição que produz adesões fibrosas ou ósseas entre as superfícies articulares da ATM. A anquilose verdadeira da ATM tem sua etiologia associada a um ou mais dos seguintes fatores: trauma, infecção, artrite reumatoide, neoplasias, complicações cirúrgicas locais e 
extensão da anquilose intracapsular, enquanto Su-Gwan, ${ }^{(7)}$ afirma que a pseudoanquilose pode ter sua origem associada a desordens psiquiátricas, musculares, ósseas e neurológicas. ${ }^{(1-3,6-9)}$ De acordo com Su-Gwan ${ }^{(7)}$ cerca de $67,8 \%$ dos casos de anquilose são associados a trauma e $17 \%$ tem como causa infecção. De acordo com Erol, Tanrikulu e Görgun ${ }^{(10)}$ e Toyama, Kurita, Koga e Ogi, ${ }^{(11)}$ tem sido proposto que nos casos de trauma, o hematoma intraarticular, a cicatriz e a formação óssea excessiva podem originar a hipomobilidade mandibular. No caso das infecções, a anquilose geralmente se manifesta secundariamente à presença de infecções como mastoidite ou otite média, no entanto também pode desenvolverse como resultado de tuberculose, gonorreia e escarlatina, quando se disseminam por via hematogênica. ${ }^{(3,4)}$ No presente caso observou-se a presença de anquilose verdadeira com etiologia associada à otite média recorrente.

Clinicamente a anquilose da ATM caracteriza-se por assimetria facial, retrusão mandibular, desvio da região mentual para o lado afetado, sintomas usualmente presentes quando a anquilose se manifesta na infância, além de comprometimento das funções, o que leva a dificuldades de mastigação e deglutição, dificuldades na fala, além de má higiene bucal. $^{(1-11)}$ No caso apresentado a paciente desenvolveu a anquilose na fase adulta, portanto, apresentou como sintomatologia dificuldade na mastigação, deglutição, fonação além da higiene bucal deficiente. Os recursos imagenológicos empregados no diagnóstico da anquilose da ATM são variáveis. Pode-se utilizar a radiografia panorâmica, que irá mostrar uma imagem com deformidade articular, com perda total de espaço articular e formação óssea anormal ao redor da articulação, contudo não revela a natureza e a extensão total da patologia mostrando apenas a relação medial e lateral da massa óssea e seu envolvimento com estruturas vitais. ${ }^{(12)}$ A tomografia computadorizada apresenta uma maior riqueza de detalhes, como por exemplo, a redução do espaço articular, e a presença de crescimento ósseo anormal, podendo descartar outras hipóteses de diagnóstico, como côndilo bífido e outras alterações morfológicas e patológicas da ATM. ${ }^{(12,13)} \mathrm{O}$ diagnóstico definitivo foi feito relacionando-se os achados clínicos com as imagens de radiografia panorâmica e tomografia computadorizada.

O tratamento da anquilose da ATM é cirúrgico, composto por artroplastia para remoção da massa anquilótica e remodelação do côndilo e da cavidade articular. A utilização de um material interposicional para prevenir a recidiva após a artroplastia tem sido amplamente discutida. Uma variedade de materiais interposicionais tem sido utilizada, 
incluindo fáscia e musculo temporal, derme, cartilagem auricular, gordura, silicone e vários metais. ${ }^{(14)} \mathrm{O}$ retalho de musculo temporal é o material interposicional usualmente utilizado na artroplastia para tratamento da anquilose, pois apresenta como vantagens a natureza autógena, resiliência, suprimento sanguíneo adequado, proximidade da articulação, além de fornecer a transferência de um tecido vascularizado para região articular. $^{(3,6,8,15)}$ No caso relatado optouse por tratamento cirúrgico composto por artroplastia interposicional, sendo realizada a ressecção do bloco ósseo, seguida pela reconstrução condilar, de modo que o novo côndilo estivesse adaptado à cavidade articular e aos movimentos mandibulares. Como medida preventiva a uma possível recidiva, realizou-se a interposição de retalho do músculo temporal, com as vantagens do mesmo possuir leito doador próximo ao leito receptor, ausência de comprometimento do suprimento vascular, pois o mesmo trata-se de um retalho pediculado, além do retalho exercer a função de uma nova articulação, uma vez que na anquilose a articulação é substituída por tecido ósseo.

A recidiva é o maior desafio no tratamento da anquilose da ATM, a utilização de material interposicional no transcirúrgico e a fisioterapia pós-operatória são decisões terapêuticas importantes na prevenção da recidiva da anquilose. O período pós-operatório imediato é o mais critico para o sucesso do tratamento da anquilose na ATM, além da fisioterapia vigorosa, a utilização de medicamentos para controle da dor pós-operatória por um período de 2 a 4 semanas e mobilização passiva e contínua são decisões terapêuticas fundamentais para manter os resultados obtidos durante a cirurgia e prevenir a hipomobilidade pós-cirúrgica secundária a presença de adesões fibrosas. ${ }^{(3,5,8,11)}$ No caso um a paciente foi submetida a fisioterapia rigorosa, com realização de sessões semanais por uma período de seis meses. Ela encontra-se em proservação há 8 anos sem sinais de recidiva.

\section{CONSIDERAÇÕES FINAIS}

A artroplastia interposicional com retalho do músculo temporal representa uma excelente alternativa para o tratamento de paciente com anquilose da ATM em fase adulta, por se tratar de um material de interposição autógeno, e apresentar vantagens morfológicas como proximidade do leito doador em relação ao leito receptor e manutenção da vascularização, características que diminuem consideravelmente a morbidade.

Revista Bahiana de Odontologia. 2013 out;4(2):129-137 


\section{REFERÊNCIAS}

1. Vasconcelos BCE, Porto GG, Bessa-Nogueira RV, Nascimento MMM. Surgical treatment of temporomandibular joint ankylosis: Follow-up of 15 cases and literature review. Med Oral Patol Oral Cir Bucal. 2009;14(1):34-8.

2. Long X, Li X, Cheng Y, Yang X, Qin L, Qiao Y, et al. Preservation of disc for treatment of traumatic temporomandibular joint ankylosis. J Oral Maxillofac Surg. 2005;63(7):897-902.

3. Figueiredo LMG, Paraguassú GM, Valente ROH, Costa WRM, Trindade SC, Sarmento VA. Anquilose da articulação temporomandibular tratada por artroplastia interposicional com enxerto costocondral: relato de caso clínico. Rev. Cir. Traumatol. Buco-Maxilo-Fac. 2012;12(2):47-52.

4. Ko EWC, Huang CS, Chen YR. Temporomandibular Joint Reconstruction in Children Using Costochondral Grafts. J Oral Maxillofac Surg 1999; 57(7):789-798.

5. Kaban LB, Bouchard C, Troulis MJ. A Protocol for Management of Temporomandibular Joint Ankylosis in Children. J Oral Maxillofac Surg 2009;67(9):1966-78.

6. Manganello-Souza LC, Mariani PB. Temporomandibular joint ankylosis: Report of 14 cases. Int. J. Oral Maxillofac. Surg. 2003;32(1): 24-29.

7. Su-Gwan K. Treatment of temporomandibular joint ankylosis with temporalis muscle and fascia flap. Int. J. Oral Maxillofac. Surg. 2001;(3)30:189-193.

8. Al Kayat A, Bramley P. A modified pre-auricular approach to the temporomandibular joint and malar arch. Br J Oral Surg 1979: 17(2):91-103.

9. Vasconcelos BCE, Bessa-Nogueira RV, Cypriano RV. Tratamiento de la anquilosisde la articulación temporomandibular por artroplastia simple. Med Oral Patol Oral Cir Bucal 2006;11(1):E66-9.

10. Erol B, Tanrikulu R, Görgün B. A clinical study on ankylosis of the temporomandibular joint. Journal of Cranio-Maxillofacial Surgery 2006;34(2):100-106.

11. Toyama M, Kurita K, Koga K, Ogi N: Ankylosis of the temporomandibular joint developing shortly after multiple facial fractures. Int J Oral Maxillofac Surg 2003;32(4):360362.

12. Sales MAO, Oliveira JX, Cavalcanti MGP. Computed Tomography Imaging Findings of Simultaneous Bifid Mandibular Condyle and Temporomandibular Joint Ankylosis: Case Report. Braz Dent J 2007;18(1):74-77. 
13. El-Hakim IE, Metwalli SA. Imaging of temporomandibular joint ankylosis. A new radiographic classification. Dentomaxillofac Radiol 2002;31(1):19-23.

14. Chossegros C, Guyot L, Cheynet F, Blanc JL, Gola R, Bourczac Z et al. Comparison of different materials for interposition arthroplasty in treatment of temporomandibular joint ankylosis surgery: long-term follow-up in 25 cases. Br J Oral Maxillofac Surg 1997:35(3): 157-160.

15. Kaban LB. Acquired Abnormalitities of the Temporomandibular Joint. Em: Kaban LB, Troulis MJ. Pediatric Oral and Maxillofacial Surgery. Philadelphia: WB Saunders; 2004. 34075. 